\title{
Characterization of the transcripts and protein isoforms for cytoplasmic polyadenylation element binding protein-3 (CPEB3) in the mouse retina
} Xiang-Ping Wang ${ }^{1}$ and Nigel GF Cooper*1,2

\author{
Address: ${ }^{1}$ Department of Anatomical Sciences and Neurobiology, Health Sciences Campus, 500 S. Preston Street, University of Louisville, \\ Louisville, KY, USA and ${ }^{2}$ Department of Ophthalmology and Visual Sciences, Health Sciences Campus, 301 E. Muhammad Ali Boulevard, \\ University of Louisville, Louisville, KY, USA \\ Email: Xiang-Ping Wang - x0wang04@gwise.louisville.edu; Nigel GF Cooper* - nigelcooper@louisville.edu \\ * Corresponding author
}

Published: I4 December 2009

BMC Molecular Biology 2009, 10:109 doi:10.1186/1471-2199-10-109
Received: 17 April 2009

Accepted: 14 December 2009

This article is available from: http://www.biomedcentral.com/I47I-2199/10/109

(c) 2009 Wang and Cooper; licensee BioMed Central Ltd.

This is an Open Access article distributed under the terms of the Creative Commons Attribution License (http://creativecommons.org/licenses/by/2.0), which permits unrestricted use, distribution, and reproduction in any medium, provided the original work is properly cited.

\begin{abstract}
Background: Cytoplasmic polyadenylation element binding proteins (CPEBs) regulate translation by binding to regulatory motifs of defined mRNA targets. This translational mechanism has been shown to play a critical role in oocyte maturation, early development, and memory formation in the hippocampus. Little is known about the presence or functions of CPEBs in the retina. The purpose of the current study is to investigate the alternative splicing isoforms of a particular CPEB, CPEB3, based on current databases, and to characterize the expression of CPEB3 in the retina.

Results: In this study, we have characterized CPEB3, whose putative role is to regulate the translation of GluR2 mRNA. We identify the presence of multiple alternative splicing isoforms of CPEB3 transcripts and proteins in the current databases. We report the presence of eight alternative splicing patterns of CPEB3, including a novel one, in the mouse retina. All but one of the patterns appear to be ubiquitous in 13 types of tissue examined. The relative abundance of the patterns in the retina is demonstrated. Experimentally, we show that CPEB3 expression is increased in a time-dependent manner during the course of postnatal development, and CPEB3 is localized mostly in the inner retina, including retinal ganglion cells.
\end{abstract}

Conclusion: The level of CPEB3 was up-regulated in the retina during development. The presence of multiple CPEB3 isoforms indicates remarkable complexity in the regulation and function of CPEB3.

\section{Background}

Translational regulation plays a major role in temporal and spatial gene expression in a wide variety of situations. Modification of translation initiation factors lead to global regulation that controls the translation of the transcriptome as a whole. Modification of regulatory factors specifically binding to mRNA motifs in the $3^{\prime}$ or $5^{\prime}$ untranslated regions (UTRs) can modulate the translation of defined groups of mRNAs [1]. Accumulated evidence now indicates that mRNA-specific regulatory factors exist as either multi-protein complexes, such as cytoplasmic polyadenylation element binding proteins (CPEBs) [2], or multi-proteins complexes containing a non-coding RNA (siRNA or miRNAs) [3]. We now know that mRNA-spe- 
cific translational control is essential for many biological processes including development, differentiation, and nervous system plasticity. Reports on the existence of these translational control mechanisms have added another layer of complexity to our understanding of gene regulation but this has been little explored in the retina.

Cytoplasmic polyadenylation was first brought to light in the 1980s, for its role in boosting translation of quiescent maternal mRNAs during oocyte maturation when little transcription activity is present [4-6]. This emerging area has particular significance for the nervous system because it provides insight into the molecular underpinnings of synaptic plasticity. The existence of a cytoplasmic polyadenylation mediated control system became a subject of interest to neuroscientists about a decade ago when it was first investigated in the hippocampus and the visual cortex [7]. In this case, CPEB1 was shown to control the polyadenylation and translation of $\mathrm{Ca}^{2+} /$ calmodulin-dependent protein kinases $\alpha$ (CaMKII $\alpha$ ) mRNA upon N-methyl-Daspartate receptor (NMDAR) activation. Four paralogous CPEBs (CPEB1-4) have been characterized in mouse $[2,8,9]$. One of these paralogs, CPEB3, is dendritically localized in the hippocampus and was shown to be coimmunoprecipitated with glutamate receptor subunit 2 (GluR2) mRNA. The knockdown of CPEB3 mRNA with the aid of small interfering RNAs (siRNA) resulted in enhanced translation of the synaptic protein GluR2 in neurons of the hippocampus [10].

Activity-dependent synaptic plasticity refers to the ability of neurons to change their synaptic strength and efficacy in adaptation to input. It can be embodied in several forms, including changes in the amount of neurotransmitters released from presynaptic terminals $[11,12]$, alteration in the composition, density or activity of receptors/ ion channels on postsynaptic membrane [13], re-remodeling of synaptic structure [14], and an increase or decrease in the number of synapses [15]. Synaptic plasticity has long been recognized at higher levels of the central nervous system (CNS), such as the cerebral cortex [16], the hippocampus [17], the cerebellum [18], and higher levels of the visual system [19].

Recent studies of the neural retina indicate that it may share some of these characteristics of activity-dependent plasticity. For example, dark-rearing suppressed the maturational pruning of dendrites in the inner plexiform layer which normally occurs after eye-opening [20-22]. Visual deprivation elevated the expression of several synaptic related molecules in the retina $[23,24]$. Light responsiveness and oscillatory potentials were inhibited in both young and adult dark-reared animals [25]. The composition of $\alpha$-amino-3-hydroxy-5-methyl-4-isoxazole propionate receptor (AMPAR) in the retinal ganglion cells switches from predominantly GluR2-containing in the light phase to GluR2-lacking in the dark phase $[26,27]$. The molecular mechanisms controlling such events in the retina remain to be determined. A good candidate is CPEB-regulated translational control. Evidence has suggested the presence of CPEB1 in mouse retina [28], octpus retina [29], and the expression of CPEB1-4 mRNAs in embryonic Xenopus retina [30]. The current study demonstrates the existence of multiple CPEB3 transcript variants in the retina. The presence of CPEB3 protein is also shown in this tissue.

\section{Results \\ Bioinformatics analysis of transcripts and protein isoforms of CPEB3}

A previous study characterized four different alternative splicing variants of CPEB3 transcripts [9], in which two short motifs of 69 nucleotides (nt) and $24 \mathrm{nt}$ (coding for 23 amino acids and 8 amino acids, respectively) are removed individually, or concurrently. However, the structure of CPEB3 seems to be more variable than previously reported. When investigating a nucleotide database (UniGene) for CPEB3 variants, we were able to identify eight transcripts labeled here as transcript variants $1 \mathrm{a}, 1 \mathrm{~b}$, $1 \mathrm{c}, 1 \mathrm{~d}, 3,4,5$ and 6 (figure 1). With the aid of sequence alignment tools (UCSC Genome Browser Blat), we mapped each cDNA to mouse genomic DNA, and acquired the information related to alternative splicing. In addition to the two previously reported short sequences (69 $\mathrm{nt}$ and $24 \mathrm{nt}$ ) whose presence or absence results in 4 variants [9], several other alternative splicing regions were discovered and elaborated here in diagrammatic form (figure 1). A similar search for the protein databases (UniProt and NCBI) identified six distinct CPEB3 protein isoforms labeled here as isoforms 1 through 6 (figure 2). With the bioinformatics tool Vector NTI, we inferred the matches between cDNA variants and protein isoforms, and designated the same numeric names to the matching transcripts and protein isoforms (figure 1,2). Transcript $1 \mathrm{a}, 1 \mathrm{~b}, 1 \mathrm{c}$ and $1 \mathrm{~d}$ all give rise to protein isoform 1 .

In addition to the previous reported alternative splicing regions [9], one of the alternative splicing locations identified in the current study was near exon 11 . The prototypical transcripts have exon 12 immediately following exon 11 (figure 1, transcripts 1a-1d, 3, 4, and 6). However, transcript 5 has exon 11 extended, which causes a completely different 3' UTR and the omission of exon 12 (figure 1). As a result, the derived protein isoform 5 terminates with four unique amino acids (GEWK) and is devoid of the second RNA recognition motif (RRM) and the zinc finger domain (figure 2).

Another variable region identified here was located within exon 4. A $388 \mathrm{nt}$ partial exon skipping within exon 4 


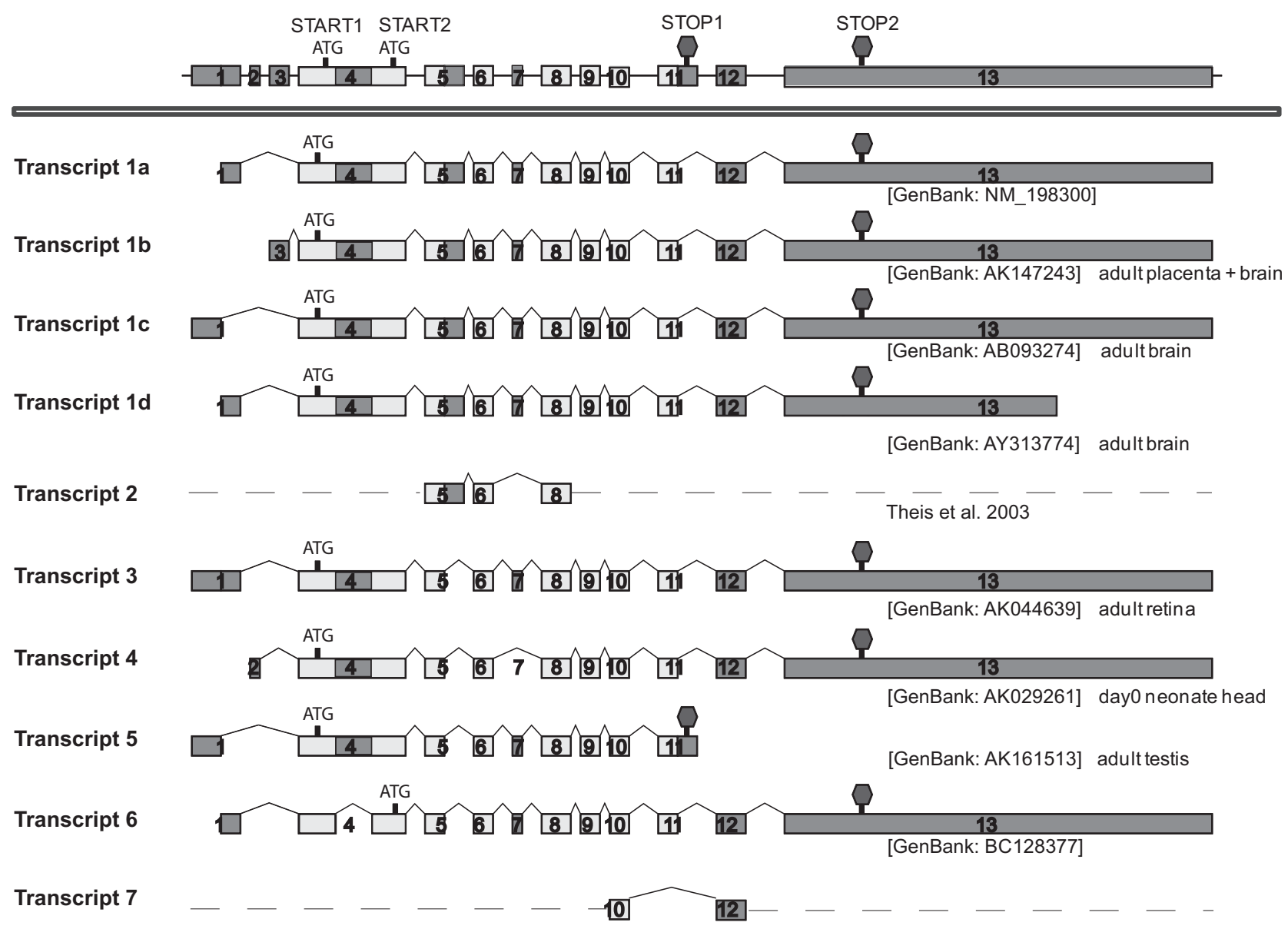

\section{Figure I}

Known transcripts of CPEB3. Upper Panel: Representation of genomic DNA sequence. Boxes represented exons, and horizontal lines represented introns. Lower Panel: CPEB3 transcripts derived from alternative splicing. Ten transcripts were shown, with their accession numbers and types of tissue (if reported to the UniGene database) given to the right. The alternative splicings of exon 4, 5, 7 and II would generate different proteins products. The alternative splicings upstream of the start codon (exon I-3) or downstream of the stop codon (exon I3) would give rise to different 5' and 3' UTRs, respectively. Dashed lines represented undetermined sequences. Partial sequence of transcript 2 (exon 5-7) was confirmed with the aid of PCR in a previous study [10], but its complete sequence was not documented in the UniGene database. Transcript 7 was a novel variant identified in the current study, of which the sequence upstream of exon 10 and downstream of exon 12 was not determined. Translational start codons and stop codons were annotated on top of the genomic DNA. Darkened boxed represented exons that could be alternatively spliced.

causes the use of an alternative translation start codon (figure 1, transcript 6), resulting in the removal of the first 216 amino acids in the derived protein (figure 2, isoform $6)$. Interestingly, this deletion removed the 197th serine, which is a phosphorylation site of CPEB3 [31].

While the splicing patterns described above could result in various protein isoforms, we found several other splicing patterns which would not lead to altered protein sequences but would rather lead to variance in their UTR regulatory regions. For example, transcripts $1 \mathrm{a}, 1 \mathrm{~b}, 1 \mathrm{c}$ use different 5'UTRs (exons 1, 2, and 3 respectively). Transcript $1 \mathrm{~d}$ uses a different 3 ' UTR (via the use of an alternative polyadenylation signal in exon 13). Such variability is the result of differentially regulated transcriptional initiation and/or termination; it most likely leads to variation in the translational regulation of the specific transcripts. These interesting findings indicate the existence of a previously unrecognized complex regulatory control system for CPEB3 transcription and translation. 


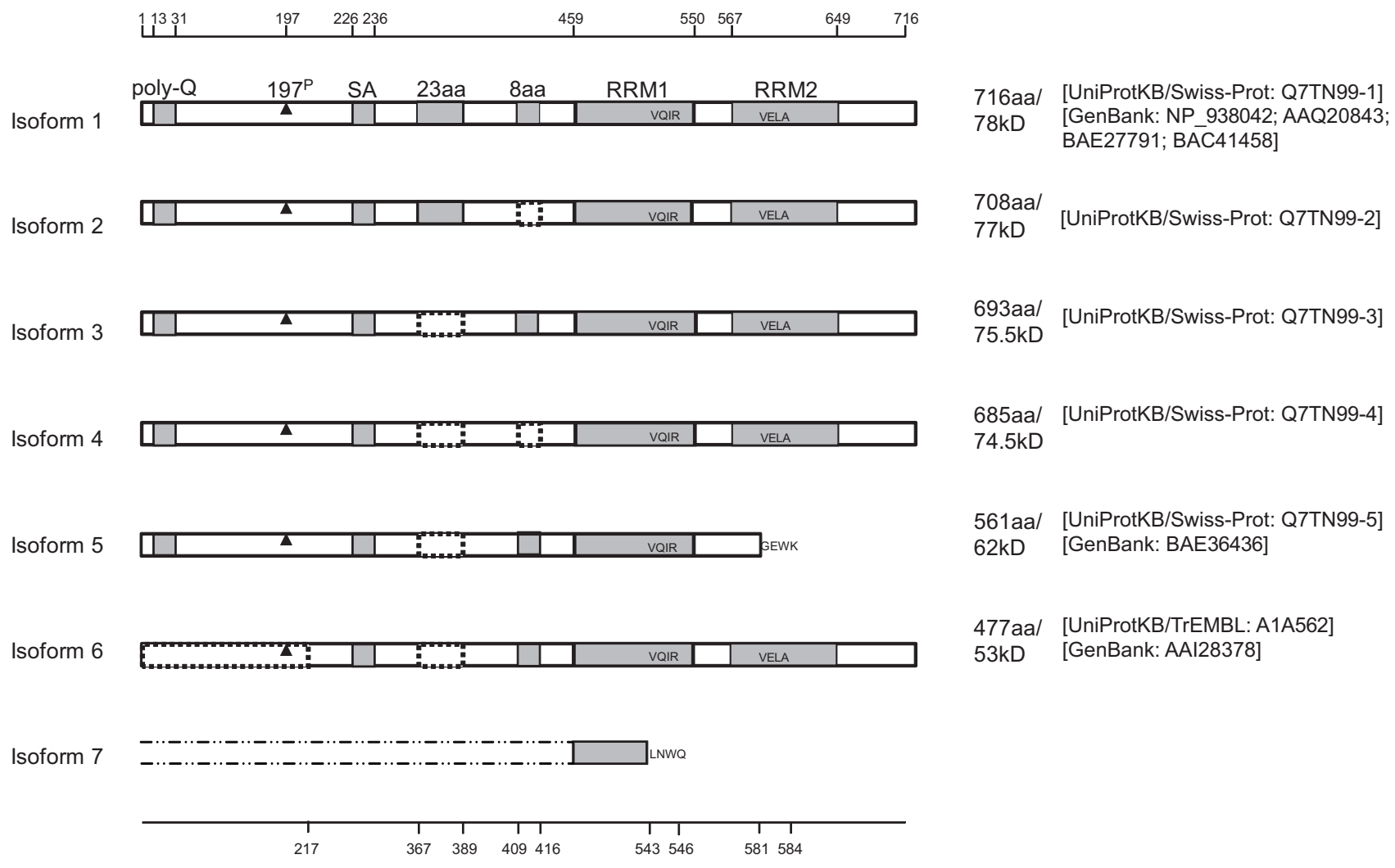

\section{Figure 2}

Known isoforms of CPEB3 proteins. Gray boxes represented possible functional motifs. Dash-lined boxed represented deletions. For simplicity, the names of the motifs were only labeled in isoform I. Poly-Q (poly-glutamine) and SA (poly serinealanine) were two unique motifs of CPEB3 that were absent in the other three CPEBs. In the current study, each of the seven isoforms was named corresponding to the same numbered cDNA transcripts depicted in figure I. Protein isoform I was the longest (7I6 aa) and may be derived from cDNA transcripts Ia-Id. One possible polymorphorism was located at the $372^{\text {th }}$ amino acid of CPEB3 isoform I: it was an N (asparagine) in [UniProtKB/Swiss-Prot: Q7TN99-Q7TNI0I] and [GenBank: AAQ20843] but a P (proline) in [GenBank: NP 938042, BAE2779I, BAC4I458]. Although the sequence of [GenBank: BAC4|458] was reported as 722 aa, we presume it was 716 aa, since the first 6 amino acids QQAAQT preceding the $7^{\text {th }}$ amino acid $M$ (methionine) was likely to be falsely generated by the prediction software. Isoform 7 was derived from computational translation based on the novel transcript 7 identified in the current study. The upstream sequence of this isoform was yet to be determined; but the in-frame translation of the identified sequence would result in truncated RRMI ending with four unique amino acids (LNWQ) and removal of RRM2. 197P represented the 197th serine, a phosphorylation site [31]. The positions of the gray-box and dash-lined-box motifs were indicated at the top and the bottom, respectively. The lengths, molecular sizes and accession numbers were indicated to the right.

Several variants including a novel variant of CPEB3 are identified experimentally in the retina. One of the variants is selectively expressed among different tissue-types

We next investigated the expression of CPEB3 mRNA within the P60 mouse retina. Regular RT-PCR studies demonstrated that CPEB3 is present in the retina (figure 3a). We further investigated which of the known CPEB3 transcripts identified through our bioinformatics analyses are expressed in the retina. The primer sets for RT-PCR were designed to span exon 5-7, around exon 11, and the partial exon skipping site within exon 4 (figure $3 \mathrm{~d}$, table 1 , table 2). Since one amplicon may correspond to more than one transcript (figure 1, figure $3 \mathrm{~d}$ ), for our purposes, we named each amplicon as an alternatively spliced "pattern" with a descriptive name rather than a numeric name. For example, the exon 5-7 region has four patterns $("+69+24 ", "-69+24 ", "+69-24 "$, and "-69-24"), and the exon 11 region has two patterns ("exon 11 extension", or "exon 11 + exon 12"). The patterns within each splicing region are exclusive of one another. Each pattern corre- 
Table I: Primers used in RT-PCR.

\begin{tabular}{|c|c|c|}
\hline Gene & Primer name & Primer sequence \\
\hline \multirow[t]{2}{*}{$\beta$-actin } & fwd & 5'-TGAAGATCAAGATCATTGCTCC-3' \\
\hline & rev & 5'-TTAAAAAAACAAAGCCATGCC-3' \\
\hline MAPKI & fwd & 5'-GCATGGTTTGCTCTGCTTATGA-3' \\
\hline MAPKI & rev & 5'-ATTTTTATCTCTCTTAGGGTTCTTTGACAG-3' \\
\hline \multirow{18}{*}{ CPEB3 } & fwd (f) & 5'-CATCAAGGATAAACCGGTGC-3' \\
\hline & $\operatorname{rev}(r)$ & 5'-GAAGAATGGGGCAAACTTCC-3' \\
\hline & $\# 1$ & 5'-TGTCAATGTCGTTGTGTTGAAGTTGC-3' \\
\hline & $\# 3$ & 5'-GACTCCCACACCACAAGGATACACA-3' \\
\hline & $\# 4$ & 5'-GAAGGCGTCTTCAAAGGGAAAGAGA-3' \\
\hline & $\# 5$ & 5'-TATGATAAGGACTGACCATGAGCCTCTG-3' \\
\hline & $\# 7$ & 5'-AGGAGCTATGGGCGGAGACGA-3' \\
\hline & $\# 8$ & 5'-GCTGAGTCCCCAATGCCTTAGC-3' \\
\hline & $\# 13$ & 5'-CCCGTTTGTCAATGTCGTTGTGTT-3' \\
\hline & $\# 16$ & 5'-AAGGATAAACCGTTGAACTGGCA-3' \\
\hline & $\# 17$ & 5'-CATGAGCCTCTGAAAGGTAAACACT-3' \\
\hline & $\# 18$ & 5'-AAGACCGACCTCGTCTCCGC-3' \\
\hline & $\# 19$ & 5'-CATGAGCCTCTGAAAGGACGC-3' \\
\hline & $\# 20$ & 5'-GAAGACCGACTGTTAAGTGCCATA-3' \\
\hline & \#21 & 5'-TTCGAGCTGTTGAACTGGCA-3' \\
\hline & \#34 & 5'-CCGTTTGTCAATGTCGTTGTGT-3' \\
\hline & $\# 39$ & 5'-TCTCAGCAGCAGCAGCGG-3' \\
\hline & $\# 40$ & 5'-GCTGGGGCTGGCGGA-3' \\
\hline
\end{tabular}

lated to one or multiple transcripts. The correspondence between each pattern and potential CPEB3 transcripts were listed in table 2 .

Amplicons of the PCR reactions were separated on agarose gel, and the identities of individual bands were confirmed by sequencing. Our results from these RT-PCR studies demonstrated the presence of " $+69+24 "$ " " $-69+24$ " (figure 3b, lane 2), "exon 11 extension" (figure 3b, lane3), the "exon 11 + exon 12" (figure 3b, lane 4 upper band), and "partial exon skipping within exon 4 " splicing patterns in the retina. Additionally, a novel CPEB3 splicing pattern, "exon 11 deletion" (figure 3b, lane 4, lower band) was identified in the retina. This was the first time this latter pattern has been reported and was named here as "transcript 7" (figure 1).
In the exon 5-7 region, although only two bands were detected with RT-PCR, it is possible that more dominant transcripts "masked" weaker transcripts by competing for the same primers. Therefore, we designed separate sets of primers for each individual splicing pattern in this region to further confirm their presence or absence (figure 3c). Each specific band was purified and sequenced for confirmation. Our results demonstrated that the "+69-24" and "-69-24" splicing patterns were indeed present in the retina (figure 3c). Multiple tissues were used to determine the tissue specificity of the above splicing patterns. Of all the patterns examined, the majority did not appear to differ with respect to tissue distribution. The only exception was the "+69+24" pattern, which was expressed in the central nervous system, ovary, testis, kidney and heart, but

Table 2: The splicing patterns of CPEB3, the corresponding CРEB3 primer pairs, and the associated transcripts.

\begin{tabular}{lll}
\hline Amplicon & Primer Pair & Corresponding Transcripts \\
\hline CPEB3 & $\mathrm{f}-\mathrm{r}$ & \\
flanking $69 \mathrm{nt}$ and $24 \mathrm{nt}$ & $4-5$ & \\
Flanking exon II & $1-7$ & \\
$+69+24$ & $17-18$ & transcripts Ia-Id \\
$+69-24$ & $17-20$ & transcript 2 \\
$-69+24$ & $19-18$ & transcripts 3, 5, 6 \\
$-69-24$ & $19-20$ & transcript 4 \\
exon II extension & $3-8$ & transcript 5 \\
exon II + exon I2 & $21-13$ & transcripts Ia-Id, 3, 4, 6 \\
exon II deletion & $16-34$ & a novel transcript, transcript \\
partial exon skipping within exon 4 & $39-40$ & transcript 6 \\
\hline
\end{tabular}




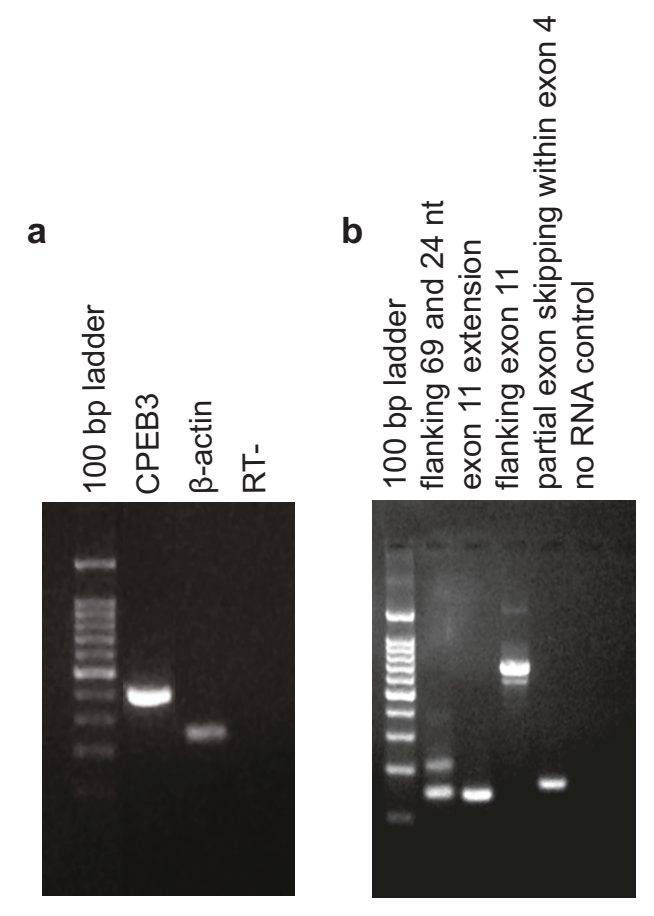

c

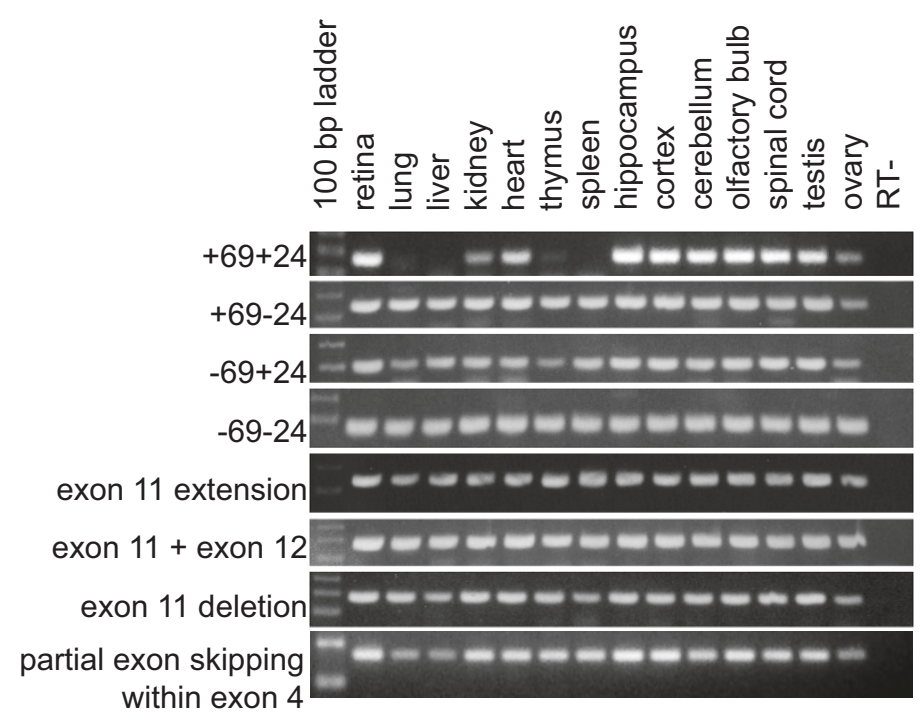

d

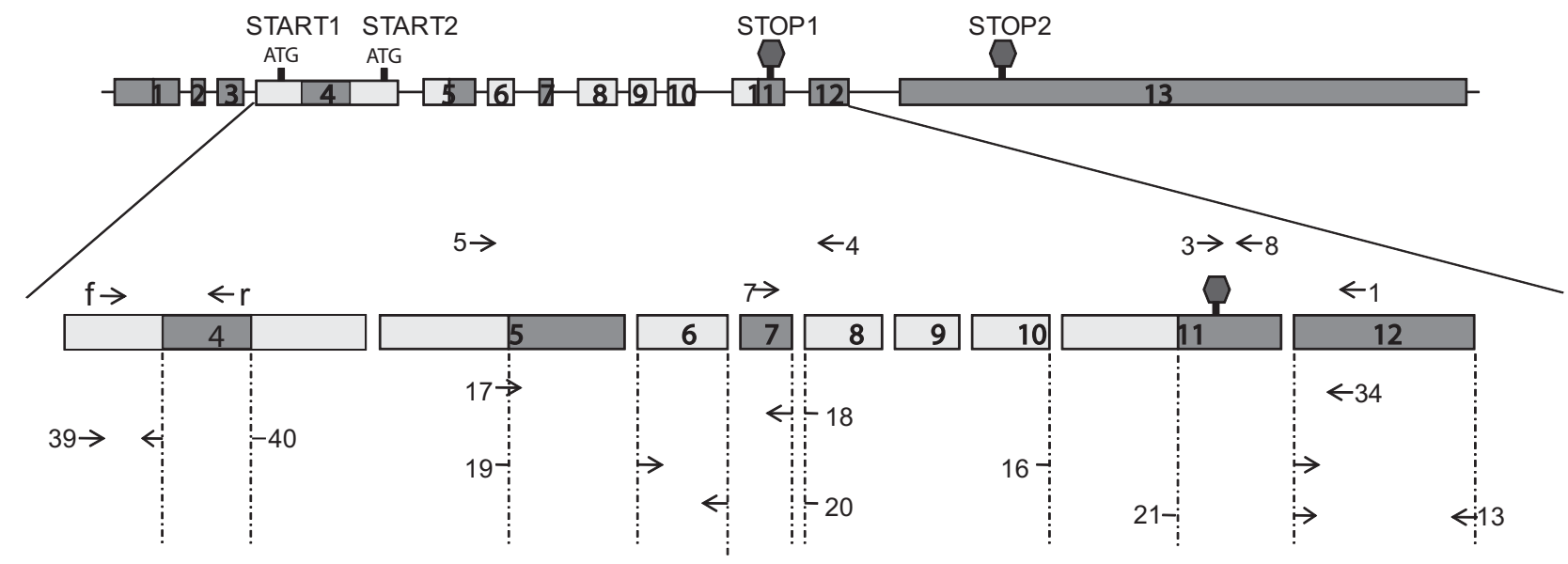

Figure 3 (see legend on next page) 
Figure 3 (see previous page)

The expression of CPEB3 as demonstrated by RT-PCR. a) CPEB3 was present in the P60 retina. b) Multiple CPEB3 transcripts were present in the retina. Different primer sets for various CPEB3 transcripts (table I, table 2) were used for PCR. Each visible band was purified and sequenced, which confirmed the presence of six splicing patterns: "+69+24" (lane2, upper band), "-69+24" (lane2, lower band), "exon II extension" (lane3), "exon II + exon I2" (lane 4, upper band); a new pattern: "exon II deletion" (lane 4, lower band), and "partial exon skipping within exon 4". But it did not rule out the presence of "+6924 " and "-69-24", since the competition for the same set of primers by a dominant pattern ("-69+24") may mask the weakly expressed variants. c) Demonstration of "+69-24" and "-69-24" patterns and comparison of tissue distribution of all patterns. Primer sets specific for each individual splicing pattern were used for PCR on thirteen different tissues from adult mice. Each specific band was purified and sequenced for identity confirmation. The results demonstrated the presence of "+69-24" and "69-24" patterns in the retina (lane 2) in addition to the 6 patterns identified in figure b). It also demonstrated the ubiquity of the majority of the patterns, with the exception of "+69+24", which was expressed in the CNS, the ovary, testis, kidney and heart, but not in the lung, liver, thymus and spleen. d) The locations of these primers were mapped to CPEB3. The corresponding relationships between the numeric primers and the splicing variants in figure a), b) and c) were listed in table 2 . Darkened boxed represented exons that could be alternatively spliced.

was absent in the thymus, spleen, lung and liver (figure $3 c)$.

\section{CPEB3 transcription is up-regulated during postnatal development of the retina}

To investigate the expression of CPEB3 during development, Taqman-based real-time PCR was used to evaluate the relative abundance of CPEB3 mRNA in the retinas of mice at seven different postnatal ages (figure 4). 18 S RNA was used for normalization. An amplicon of $79 \mathrm{nt}$ spanning exon 4 and exon 5 of CРEB3 was amplified. This amplicon was inclusive of all known CPEB3 transcripts, therefore, represented the totality of the CPEB3 transcripts. The similarity of the amplification efficiency of CPEB3 and $18 \mathrm{~S}$ primer sets were pre-validated by the manufacturer and verified in our laboratory (data not shown). The level of CPEB3 mRNA was significantly increased throughout the postnatal development and stayed high when the animals reached adulthood (figure 4).

Since CPEB3 has multiple transcript variants in the retina, we investigated which of the particular CРEB3 transcripts were up-regulated during the period of postnatal development using SYBR Green-based realtime PCR. Mitogenactivated protein kinase 1 (MAPK1) mRNA, the transcription level of which showed little fluctuation during development in the retina (data not shown), was used for normalization. MAPK1 primers and CPEB3 primer sets specific for each splicing pattern (table 1, table 2, figure $3 \mathrm{~d})$ were designed in-house to generate amplicons of between $75 \mathrm{bp}$ and $150 \mathrm{bp}$ for robust amplification. Similar amplification efficiencies (89\%-94\%) were reached under optimized conditions for all primers sets, allowing quantitative comparisons between CPEB3 and MAPK1, and among different CPEB3 splicing patterns (figure 5). The data on seven different age groups demonstrated that all CPEB3 transcript patterns examined had similar trends of postnatal-related increases (figure 5). This is consistent with our previous findings (figure 4).

Comparisons of the relative abundance of transcript patterns within each region (figure 5) demonstrated that within exon 5-7 region, the "-69+24" pattern was the most abundant, and the "+69-24" pattern was the least abundant. Within the region surrounding exon 11, the prototypical "exon $11+$ exon 12 " was the most abundant, while both "exon 11 extension" and "exon 11 deletion" were much less abundant. Of the eight transcript patterns, the three most abundant were "-69+24", "exon 11 + exon 12", and "partial exon skipping within exon 4 " across all ages.

\section{CPEB3 protein is regulated during postnatal development of the retina}

We investigated the relative abundance of CPEB3 protein in the developing retina with the aid of western blots. Two antibody-labeled bands with molecular weights of $~ 130$ $\mathrm{kD}$ and $\sim 75 \mathrm{kD}$ respectively were identified in western blots and were both diminished by pre-adsorption with recombinant CPEB3 protein or by depletion of CPEB3 in Hela cells (figure 6). The $\sim 75 \mathrm{kD}$ band could be isoform 3 or isoform 4 based on their predicted sizes. The intensity of the $\sim 75 \mathrm{kD}$ band increased significantly during postnatal development of the retina, which was consistent with the postnatal increases in the level of CPEB3 transcripts (figure 4,5 ). The $\sim 130 \mathrm{kD}$ band could be a dimer, a preprotein, or a prion form of CPEB3. Since the $\sim 130 \mathrm{kD}$ band was not weakened in reducing and denaturing conditions (by adding 1,4-dithioerythritol or beta-mercaptoethanol and boiling), it seems less likely to be a dimer. The possibility of it being a pre-protein needs further evidence. The transcripts shown here do not indicate the presence of a protein larger than $\sim 78 \mathrm{kD}$, neither is there any such protein evident in the UniProt database. However, a previous study indicated the presence of a $\sim 100 \mathrm{kD}$ CPEB3 protein [10]. With the aid of a different gel/buffer 


\section{CPEB3 transcription is upregulated in the developing retina}

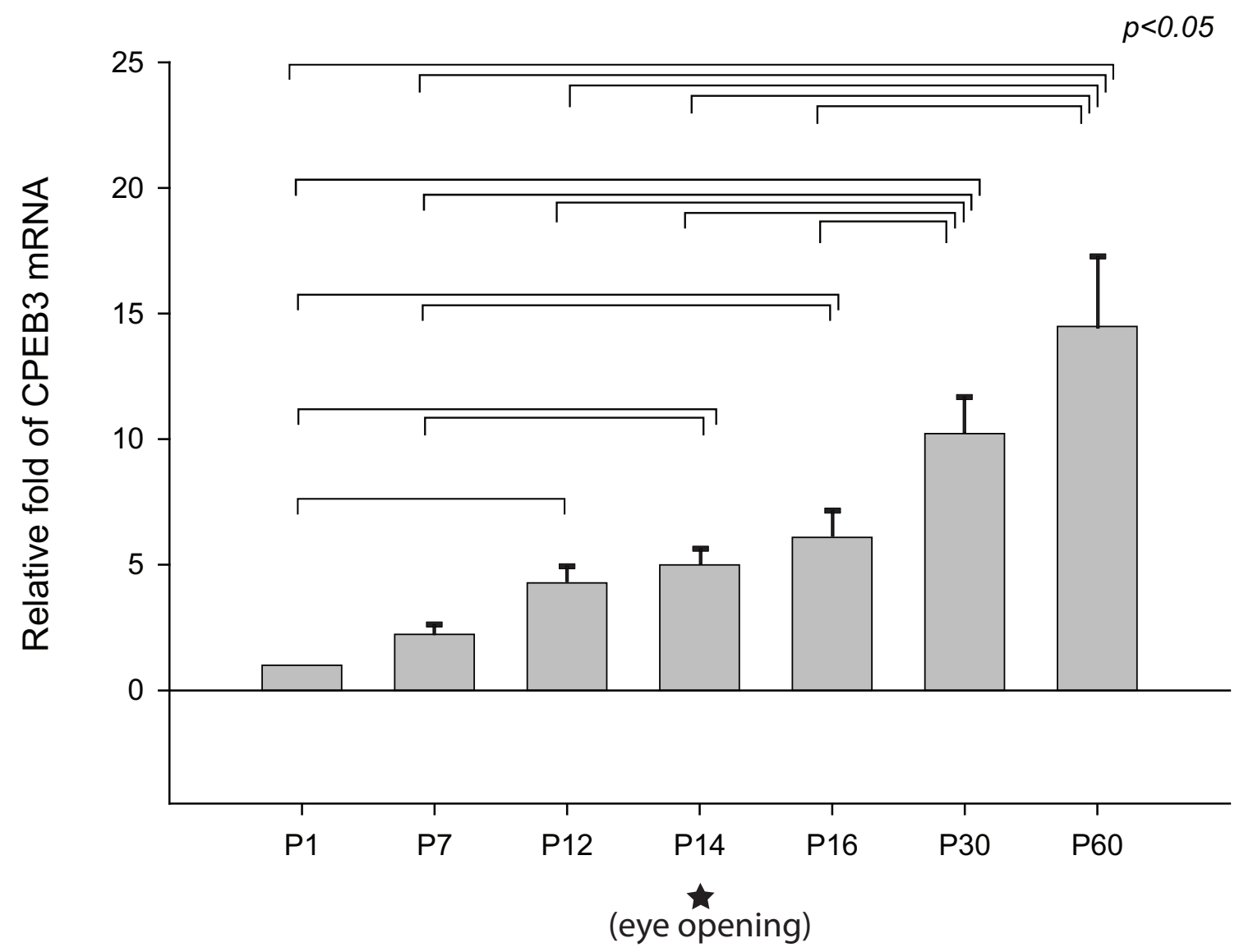

Postnatal developmental ages

\section{Figure 4}

CPEB3 mRNA during postnatal development. The relative fold change in the amount of CPEB3 mRNA was shown with the aid of real-time PCR. Seven postnatal ages flanking the eye-opening event were used for this study. For each sample, the level of CPEB3 mRNA was normalized to that of I8S RNA in the exact same sample. All experiments were repeated three times. All ages were calibrated relative to the postnatal age PI and expressed as fold changes. Statistically significant differences were found by ANOVA between sets of two bracketed ages as indicated $(p<=0.05)$. For each age, the number of samples $n$ $>=6$. Error bars represented standard error of the mean (SEM). The asterisk indicated the approximate time of eye-opening. The results demonstrated that CPEB3 was significantly up-regulated in the retina from PI to PI2 (before eye-opening), and from PI6 to P30 (after eye opening), and reached maximum in the adulthood (P60).

system and different protein standards, we have since found that the larger band appeared to be around $97 \mathrm{kD}$. Therefore, it seems likely that the $100 \mathrm{kD}$ band in the prior study and the $130 \mathrm{kD}$ band in our study are of the same identity. We can only speculate that any transcripts for CPEB3 proteins larger than $78 \mathrm{kD}$ are yet to be discovered.
The possibility of it being a prion form $[32,33]$ also needs further investigation.

Some of the transcripts identified in the current study did not show distinct protein bands in western blots. This may be attributed to the relative abundance of the tran- 


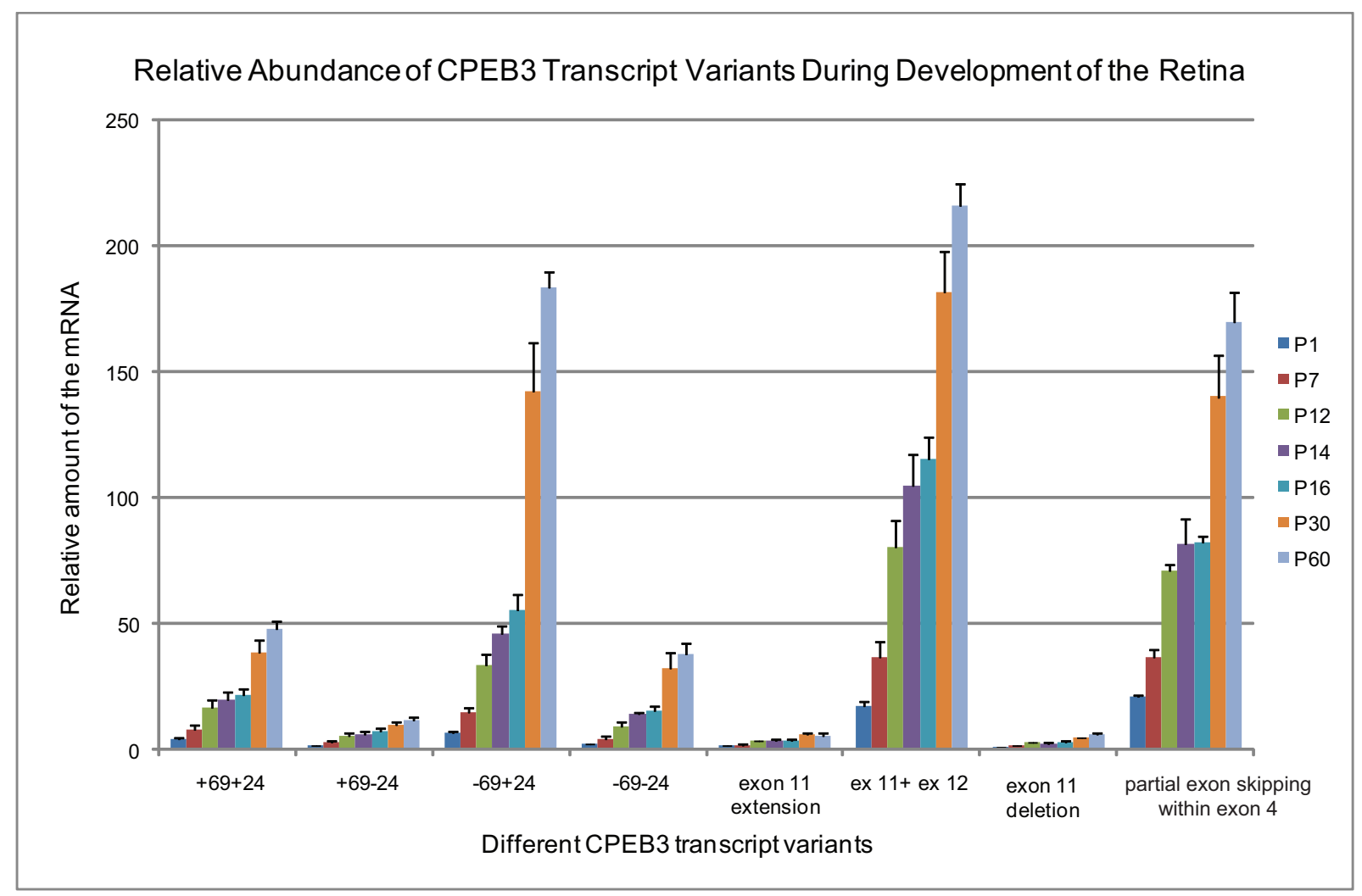

\begin{tabular}{|l|l|l|l|l|l|l|l|l|l|}
\hline Splice Pattern & $+69+24$ & $+69-24$ & $-69+24$ & $-69-24$ & ex11 ext. & ex11+ex12 & ex11 del. & ex4 part skip & \\
\hline Primer Set & $17-18$ & $17-20$ & $19-18$ & $19-20$ & $3-8$ & $13-21$ & $16-34$ & $39-40$ & MAPK1 \\
\hline Efficiency & 91.4 & 94.0 & 91.8 & 94.4 & 90.9 & 91.8 & 89.1 & 90.1 & 90.1 \\
\hline SEM & 1.1 & 2.0 & 1.1 & 2.5 & 0.9 & 1.1 & 0.6 & 0.8 & 0.7 \\
\hline
\end{tabular}

\section{Figure 5}

Relative abundance of different CPEB3 transcript patterns during development of the retina. The levels of each mRNA was normalized to the level of MAPKI mRNA in the same sample. All the transcript variants demonstrated similar increasing trends during postnatal development. The relative abundance at any given age demonstrated that the "-69+24" pattern was the most abundant in exon 5-7 region; the "ex II + ex I2" pattern was the most abundant in the region surrounding exon II; and "partial exon skipping within exon 4" pattern was abundant. For age PI4, $n=3$; for all the other ages, $n=4$. Error bars represented standard error of the mean (SEM). The amplification efficiencies for all the primer sets used in realtime PCR were listed in the table below the graph.

script (a result of transcriptional regulation), or the variability in the 5' UTRs and 3' UTRs of the transcripts (leading to translational regulation). It is likely that not all transcripts are translated with equal efficiency under the current paradigm. Therefore, some protein isoforms may be expressed at very limited amounts, which are below the level of detection with the method used here. However, such isoforms may be expressed more robustly under other more appropriate, but unknown stimuli.

\section{CPEB3 transcripts are expressed in the inner retina}

With the aid of in situ hybridization and light microscopy we identified which types of cells in the retina express CPEB3 mRNA in the P60 mouse. To ensure specificity, the in situ hybridization probes were designed in a region where little homology was found between CPEB3 and the other CPEBs. A sense probe complementary to the antisense probe was used as a negative control. The results (figure 7) demonstrated that CPEB3 was localized pre- 
a

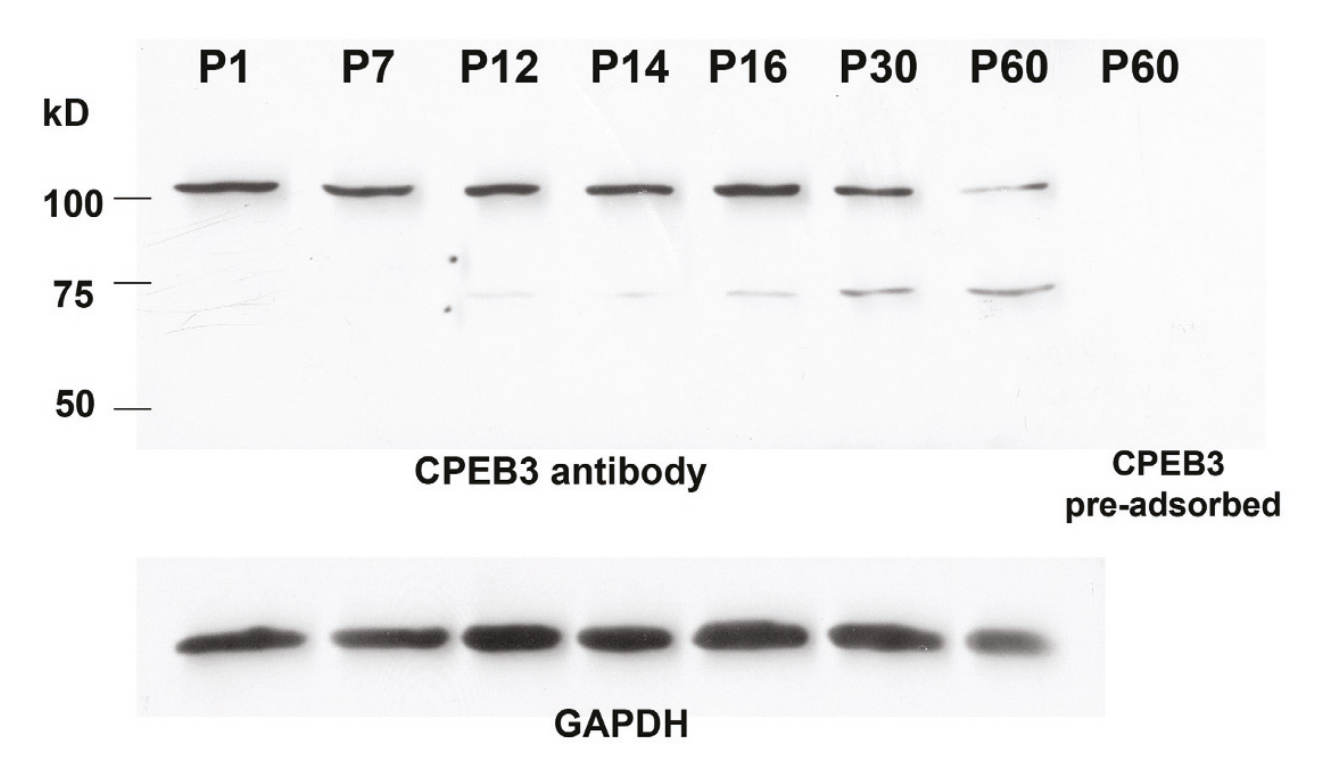

b

\section{Figure 6}

The expression of CPEB3 proteins in the retina. a) The regulation of CPEB3 protein during the postnatal development of the retina. CPEB3 western blot on retinal samples from seven different postnatal ages showed that the $75 \mathrm{kD}$ band protein was increased during the development. Another band at 130 kD was also present in the retina. Both bands diminished when the antibody was pre-adsorbed with the recombinant CPEB3 protein (the last lane). GAPDH was used as a loading control. b) Both of the $75 \mathrm{kD}$ and the $130 \mathrm{kD}$ bands diminished when Hela cells were transfected with CPEB3 siRNA. Cells in the negative control were treated with a negative control siRNA. GAPDH was used as a loading control.

dominantly in the retinal ganglion cell (RGC) layer, and to a less extent, in the inner margin of the inner nuclear layer (INL). It was not clear if CPEB3 mRNA was also present in the plexiform layers due to the limited resolution of this technique.

\section{CPEB3 protein is expressed in the retina}

To confirm the expression pattern of CPEB3 mRNA and to better define the cell types containing CPEB3 protein, fluorescence immunocytochemistry with an antibody to CPEB3 was used. A pattern was observed which was similar to that seen for the localization by in situ hybridization. CPEB3 protein was strongly expressed in cells located within the RGC layer, and to a less extent, within cells of the inner boundary of the INL (figure 8,9 ). Both the inner plexiform layer (IPL) and the outer plexiform layer (OPL) also showed pronounced immunolabeling of CPEB3. To define the type of cells which express CPEB3 we used double immunolabeling with cell type-specific markers in combination with CPEB3. The ganglion cell-specific marker microtubule-associated protein 1a (Map1a)
[34,35], and the cholinergic amacrine cell marker choline acetyl transferase (ChAT) [36-41], were used. Confocal microscope images indicated that most of the anti-CPEB3 labeled cells in the RGC layer were retinal ganglion cells (figure 8), and a few were displaced amacrine cells (figure 9).

\section{Discussion}

This study demonstrated for the first time that CPEB3 mRNA and protein were present in the mouse retina. Multiple CPEB3 transcripts were shown to be present in the retina. The majority of the transcripts described here appeared to have a wide tissue distribution. A novel transcript of CPEB3 ("exon 11 deletion") was discovered and was present in multiple tissues including the retina. In addition, the " $+69+24$ " transcript pattern had various tissue distribution and was expressed in CNS tissues. The results also demonstrated for the first time that all CPEB3 transcripts were up-regulated in the mouse retina during postnatal development and reached maximum in adulthood. 


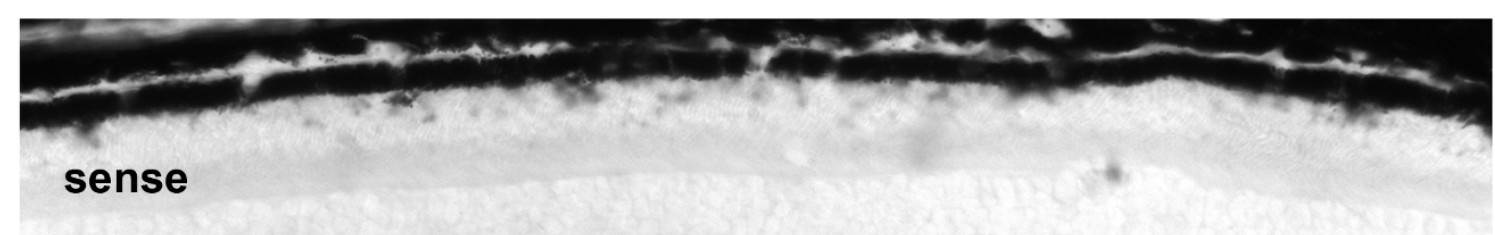

ONL

OPL

INL

IPL
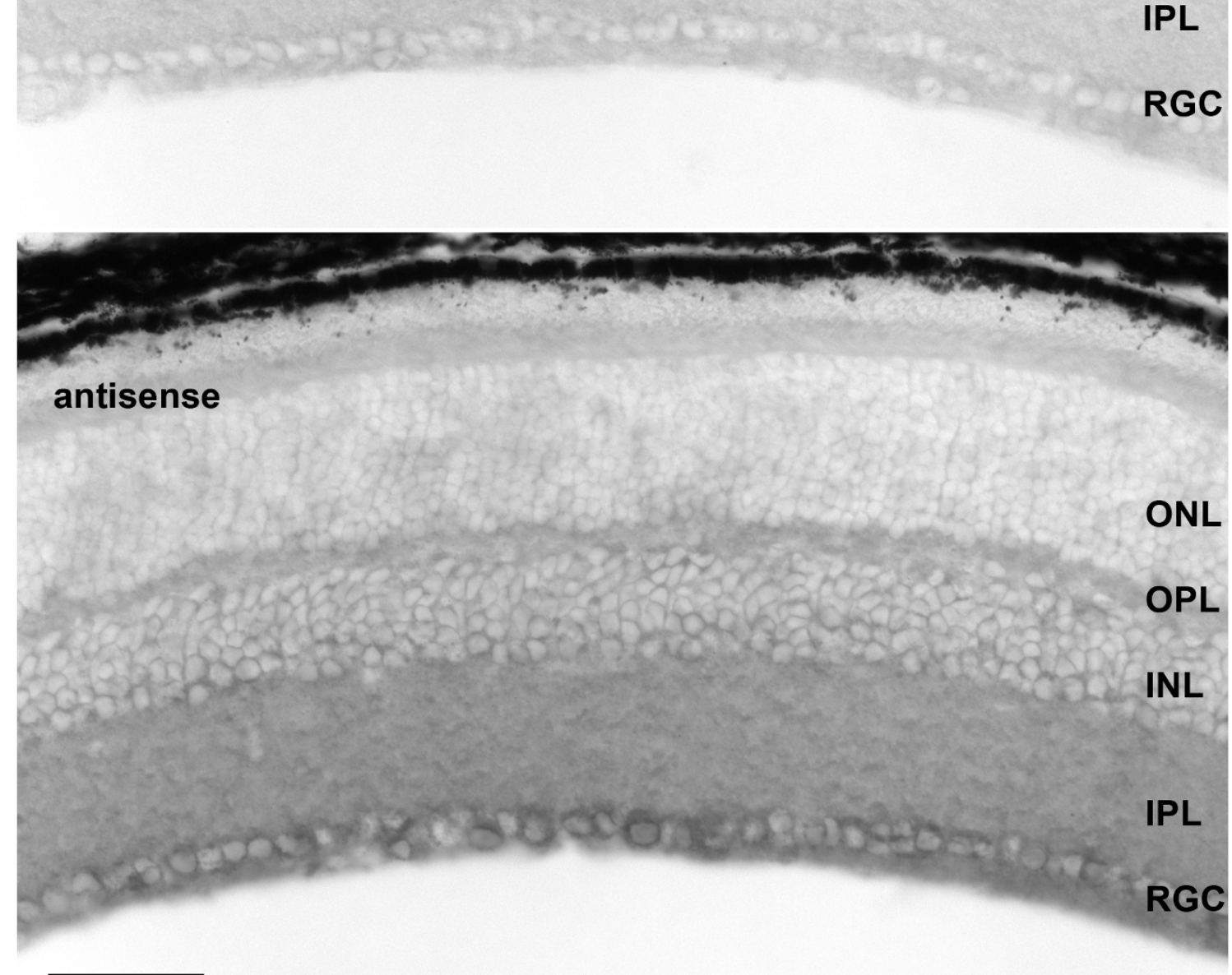

\section{Figure 7}

In situ hybridization of CPEB3 on P60 mouse retina. Sense probe complementary to the antisense probe was used for the negative control. The probes were designed in a region with no significant homology to any other CPEB to ensure specificity. The expression of CPEB3 mRNA was located mostly in the RGC layer and to a lesser extent, the INL. Scale bar represented $50 \mu \mathrm{m}$. ONL: outer nuclear layer; OPL: outer plexiform layer; INL: inner nuclear layer; IPL: inner plexiform layer; RGC: retinal ganglion cell layer. 

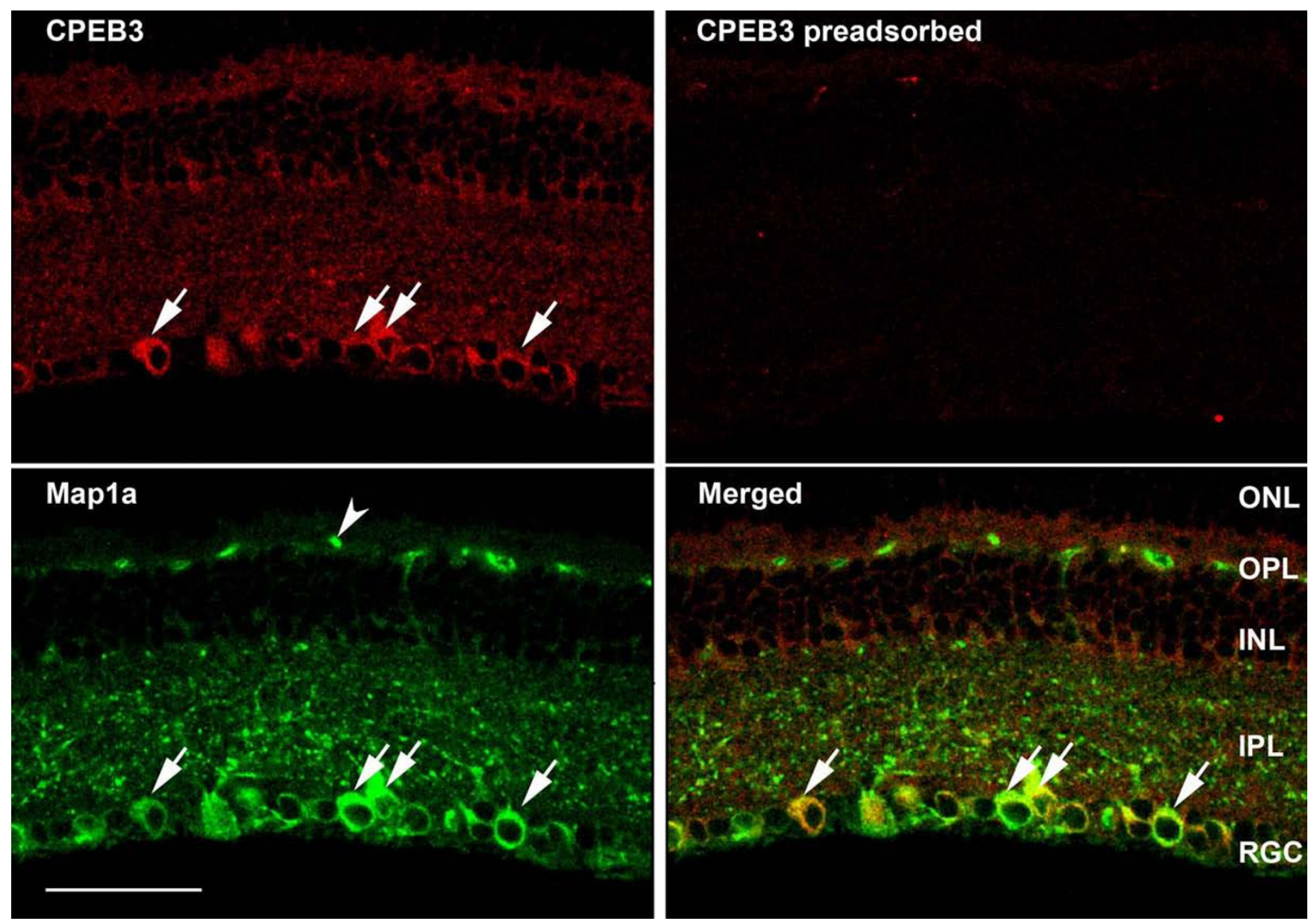

Figure 8

The presence of CPEB3 in P60 mouse retina. We used double-immunofluorescence labeling with antibodies to CPEB3 and Map la. Mapla has been demonstrated as a marker for retinal ganglion cells. Most cells in the RGC layer were doublelabeled with CPEB3 and Mapla antibodies (arrows), suggesting that they are retinal ganglion cells. The INL was also labeled with CPEB3 antibody, with the innermost cells more intensely labeled. Both the IPL and the OPL were labeled with CPEB3 antibody. The Mapla containing structures (arrowhead) in the OPL were non-specific since they also appeared in no primary control. The scale bar represented $50 \mu \mathrm{m}$.

\section{CPEB3 variants provide for a higher level of regulation complexity than has been hitherto recognized}

The large number of variants in the coding region, together with variances in the 5' and 3' UTRs of CPEB3 (figure 1) provides evidence for an unexpected level of regulatory and functional complexity of CPEB3. First of all, the differences in CPEB3 protein sequences (figure 2) add to the complexity of its function which may involve different temporal and spatial patterns. The alternatively used sequences may generate discrete "tags" that serve as hallmarks for localization of the protein, catalysis by discrete kinases/phosphatases/endopeptidases, or interaction with different protein partners. As a result, the activation, inhibition or turnover of CPEB3 proteins may also be affected. For instance, the 8-amino acids motif (present in isoform 1, 3, 5, and 6, figure 2) presumably harbors phosphorylation sites for CaMKII, protein kinase A (PKA) and p70S6 kinases [9]. The functional significance of the 23-amino acids motif (present in isoform 1 and 2, figure 2) and the 4-amino acids motif GEWK (present only in isoform 5, figure 2) is unknown, but is of interest for future studies. The RNA recognition motifs (RRMs) of isoforms 5 and 7 of CPEB3 were altered, which would likely to impact their substrate specificities, similar to an effect previously proposed for CPEB1 [42].

Secondly, the regulatory properties of CPEB3 can stem from the differences in the 5' UTR and 3' UTR regions of the CPEB3 mRNAs. For example, transcripts 1a, 1b, 1c, and $1 \mathrm{~d}$ all yield the same protein product, but each has a different 5' UTR or 3' UTR. The variability in the UTRs is the result of differentially regulated transcription (alterna- 

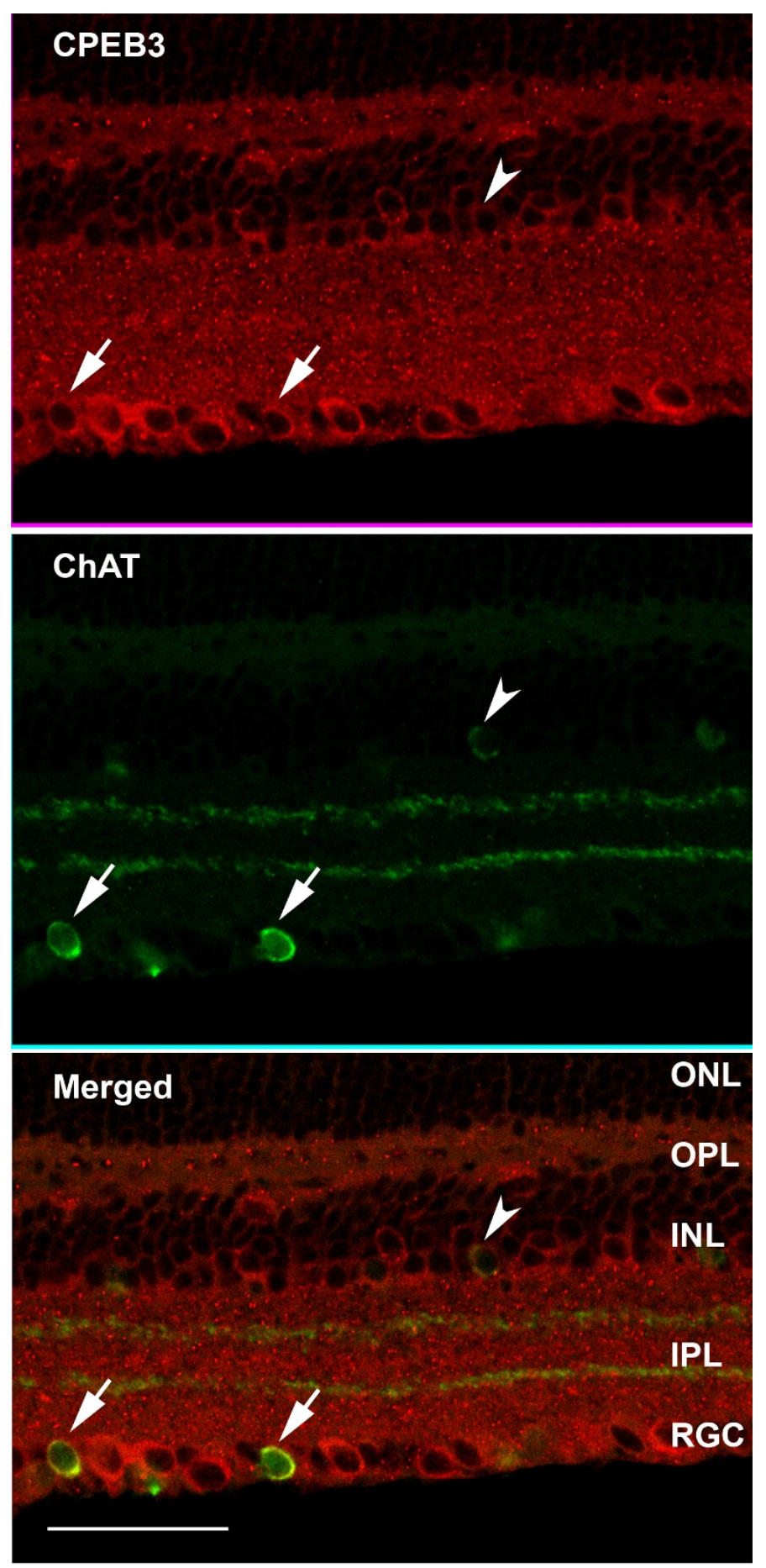

\section{Figure 9}

The presence of CPEB3 in P60 mouse retina. We used double-immunofluorescence labeling with antibodies to CPEB3 and ChAT. ChAT is a marker for cholinergic amacrine cells. A few cells in the RGC layer were double-labeled with ChAT and CPEB3 antibodies, as indicated with the arrows. This suggested that a few CPEB3 positive cells in the RGC layer were displaced amacrine cells. The size of such cells was usually smaller than those cells staining positive for both CPEB3 and Mapla. The INL was also labeled with CPEB3, with the innermost cells more intensely labeled. A few cells in the INL appeared to be double-immunopositive for ChAT and CPEB3 (arrowhead), suggesting that some CPEB3 positive cells in the INL were cholinergic amacrine cells. Both the IPL and the OPL were labeled with CPEB3. Scale bar represented $50 \mu \mathrm{m}$. 
tive transcriptional initiation and termination); such variability in the UTRs would further lead to discriminations in translational regulation. The UTRs may also harbor signal motifs such as that for mRNA localization or degradation, hence subjecting the mRNA to distinct stimuli or degradation pathways. The mechanisms for the transcriptional and translational control of CPEB3 and the functional significance of the UTR variants shown here provide fertile ground for future investigations.

\section{CPEB3 may play a role in synaptogenesis before eye opening}

The level of CPEB3 was up-regulated during the postnatal development and reached maximum abundance in adulthood (figure 4, 5). The presence of CPEB3 in the early ages may be related to a possible role during synaptogenesis. It is well established that the mammalian retina is premature at birth. The ganglion cell layer and the inner plexiform layer are recognizable at the time of birth, but the remainder of the retina is yet to be fully developed. The synaptogenesis in the IPL starts at day $3[43,44]$. Robust glutamatergic synaptic formation occurs in the second postnatal week, and synaptic sublamina becomes visible in the IPL on day 12 [45]. The rate of synaptogenesis in the IPL drops precipitously at day 15 (around the time of eyeopening) [44]. Synaptic connections in the OPL begin to develop on day 3 and are well established by day 12, when the first light response was recorded as electroretinogram (ERG) [46]. The synaptogenesis in both the IPL and the $\mathrm{OPL}$ is concurrent with the increasing abundance of CPEB3 seen during the early ages. Also noteworthy is the pronounced labeling of CPEB3 proteins in the IPL and the OPL (figure 8 and 9). This prompts the speculation that CPEB3 expression is important for the process of synaptogenesis; or alternatively, its expression is a consequence of synapse formation.

Future studies on the interactions between CPEB3 protein and mRNAs for synaptically relevant molecules, such as AMPARs, NMDARs, CaMKII, and brain-derived neurotrophic factor (BDNF) mRNAs, can be employed to clarify this issue. For example, AMPAR is involved in fast synaptic transmission. GluR2/3 and 4 are expressed before the emergence of synaptic transmission, indicating a role of AMPAR in the establishment of retinal circuitry $[47,48]$. The onset and regulation of GluR2 expression in the retina is in accordance with the process of synaptogenesis: it starts early in postnatal development, and reaches a peak before eye-opening $[48,49]$. The distribution pattern of GluR2 in the IPL alters from a disoriented pattern just after birth to a laminated pattern prior to eye-opening [49], manifesting the reorganization of synaptic circuits. The expression pattern of CPEB3 in the retina observed in our study does appear to be consistent with that of GluR2. Thus, both are expressed in the same types of cells, and both are up-regulated in the first two weeks. Given the previous notion that CPEB3 protein binds to GluR2 mRNA in hippocampal neurons and that GluR2 is a potential target of CPEB3-mediated translational regulation [10], it is plausible to conceive that CPEB3 also regulates the translation of GluR2 during synaptogenesis in the retina.

In addition to GluR2, there are several other synapticallyrelevant molecules that are localized in the RGCs and amacrine cells and are developmentally up-regulated, among which are AMPAR subunits GluR1, GluR4, NMDAR subunits NR1, NR2A, NR2B, and CaMKII $\alpha$ $[23,24,47,48]$. A U-rich hairpin loop structure in the $3^{\prime}$ UTR of mRNAs has been identified as the binding motif for CPEB4; such a motif was also recognized by CPEB3 [10]. Although other possible recognition motifs for CPEB3 protein remain to be identified, the presence of the U-rich hairpin structure in the 3' UTR of mRNAs could serve as an indicator that these mRNAs may be targets of CPEB3 regulated translational control. Potential CPEB3 targets containing the U-rich motif can be explored with bioinformatics tools, and further verified with in vitro binding assays [10] or in vivo manipulation of CPEB3 expression.

\section{CPEB3 may play a role during synaptic maturation}

Anatomical studies indicated that the retina matures at postnatal day 41 [50]. Although most morphological and neurochemical properties of the mouse retina (i.e. the number of conventional and ribbon synapses, the expression of neurotransmitters receptors) have reached the adult level at the time of eye opening $[43,51]$, the maturation of synaptic function continues for several weeks following eye-opening. The establishment of ON and OFF pathways occurs to a large extent after eye opening. The dendrites of RGCs ramifies widely in IPL during early postnatal days [52], but remodels into a predominantly monostratified form within sublamina a or sublamina b of the IPL in two to three weeks after eye opening [22]. The synaptic strength of the RGCs, measured as the frequency of spontaneous synaptic activity, is low around the time of eye opening, but surges around P25 both in spontaneous excitatory postsynaptic currents (sEPSCs) mediated by glutamate receptors and in spontaneous inhibitory postsynaptic currents (sIPSCs) mediated by GABA/glycine receptors [53]. These maturational processes following eye-opening resonate with the continuing increase of CPEB3 after eye opening. Whether such resonance is coincidental or interrelated is an intriguing topic for future studies.

\section{CPEB3 and synaptic plasticity in the adulthood}

Both our real-time PCR data and western blot data indicated that CPEB3 continued to increase during develop- 
ment and reached its highest level in adulthood. These observations provide a strong indication that CPEB3 is functional in adult retinas. Neuronal plasticity has been historically characterized as a feature of the developing CNS, but several lines of evidence indicate that some forms of synaptic plasticity are not just the privilege of developing animals.

One form of activity-driven synaptic plasticity in the adult retina is described in the course of normal diurnal light/ dark cycles. GluR2-containing AMPARs undergo rapid cycling in the RGCs and amacrine cells via endocytosis and exocytosis [26]. Synaptic quiescence in the dark drives rapid cycling resulting in the presence of AMPARs-lacking GluR2 in the synaptic membrane. On the contrary, synaptic activity in the light period inhibits cycling and stabilizes AMPAR as predominantly GluR2-containing receptors on the cell surface. Such cycling of AMPARs is also present in hippocampal neurons and plays a critical role in synaptic plasticity in the adult hippocampus $[54,55]$. Although the underlying mechanisms for AMPAR cycling are yet to be fully deciphered, one may speculate that CPEB3 plays a role in this process.

\section{Conclusion}

In conclusion, the current study demonstrated that CPEB3 is expressed in the retina. The levels of all transcripts were up-regulated during postnatal development. We assume that all of these transcripts have corresponding protein products, but under the developmental paradigm used here, not all protein products were detected. It is possible that there are other paradigms which would lead to the translation of the other transcripts. This needs to be further explored. The variability in the protein-coding regions and the UTRs indicates a remarkable degree of complexity in both the regulation and function of CPEB3.

\section{Methods \\ Bioinformatics}

For CPEB3 transcript variants, the UniGene database [56] and the UCSC Genome Browser database [57] was used. For CPEB3 protein isoforms, the UCSC mouse proteome database [58], the UniProt database [59] and the NCBI protein database [60] were used. Sequence alignments were carried out with the aid of Blast [61], UCSC Blat [62], and Vector NTI (Invitrogen, Carlsbad, CA).

\section{Animal handling and tissue preparation}

All animal experimental procedures were performed in compliance with University of Louisville IACUC animal care regulations, as well as the ARVO statement for the use of animals in ophthalmic and vision research. C57/BL6 mice were used for this study (Charles River Laboratories, Davis, CA). Mice were euthanized with CO2 followed by cervical dislocation. For RNA and protein extraction, the eyes were removed and retina dissected immediately and frozen on dry ice before proceeding to extraction. For in situ hybridization and/or immunohistochemistry, whole eyes were fixed in $4 \%$ paraformaldehyde for 12 hours at $4^{\circ} \mathrm{C}$, then dehydrated in PBS buffer with $30 \%$ sucrose for two weeks at $4^{\circ} \mathrm{C}$. Snap-freezing embedding was carried out in isopentane in a container placed on dry ice. The temperature was kept below $-70^{\circ} \mathrm{C}$ by adding crashed dry ice into isopentane. The mounted tissue was then cut 14 microns thick on a cryostat on the same day or frozen airtight at $-80^{\circ} \mathrm{C}$ for future sectioning.

\section{RNA extraction}

Frozen retina was homogenized rapidly using a PowerGen 250 homogenizer (Fisher Scientific, Pittsburgh, PA). Total RNA was extracted using RNeasy mini kit (Qiagen, Valencia, CA) following the manufacturer's instructions. The concentration of RNA was determined using a BioPhotometer (Eppendorf, Westbury, NY), and the quality of RNA decided by the ratio of $28 \mathrm{~S} / 18 \mathrm{~S}$ on an agarose gel. RNA was frozen in $-80^{\circ} \mathrm{C}$ for long term storage.

\section{RT-PCR}

$0.2 \mu \mathrm{g}$ of total RNA was used for a $20 \mu \mathrm{l}$ RT reaction using AMV reverse transcriptase (Promega, Madison, WI). $1 \mu \mathrm{l}$ of the cDNA was used for PCR. The exon-exon junction spanning, gene-specific primers for CPEB3, the control gene $\beta$-actin, and specific CPEB3 transcripts were designed in-house and obtained from IDT (Coralville, IA). Sequences of these primers are listed in table 1. PCR was carried out on a thermocycler using the following conditions: $95^{\circ} \mathrm{C} 15 \mathrm{~min}$ for initial activation; 40 cycles of: $94^{\circ} \mathrm{C} 30 \mathrm{sec}$ (denaturation), $60^{\circ} \mathrm{C}$ or $55^{\circ} \mathrm{C} 30 \mathrm{sec}$ (annealing), $72^{\circ} \mathrm{C} 30 \mathrm{sec}$ (extension); lastly, $72^{\circ} \mathrm{C} 10 \mathrm{~min}$ for extension. The resulting PCR products were visualized on $1 \%$ agarose gels and photographed. Individual bands were cut out, purified and sequenced to confirm their identities.

\section{Real-time PCR}

$0.2 \mu \mathrm{g}$ of total RNA and the high capacity cDNA archive kit (Applied Biosystems, Foster City, CA) was used for the reverse transcription. The resulting $\mathrm{CDNA}$ was diluted 1:20 and $5 \mu \mathrm{l}$ of the dilution was used for each PCR reaction. For the overall expression of CPEB3 during development, TaqMan Gene Expression Assay for CPEB3 (the mixture of gene-specific primers and gene-specific, FAM-labeled probes, ID\# Mm01204293_m1, Applied Biosystems) and TaqMan Gene Expression Assay for the endogenous control gene 18S (ID\# Hs99999901_s1, Applied Biosystems) were used. The CPEB3 primer-probe set generates a product spanning exon 4-5, which represents all known CPEB3 transcripts. PCR master mix containing Taq DNA polymerase, dNTPs and optimized reaction buffer were also obtained from Applied Biosystems. PCR reactions 
were performed with an ABI 7300 real-time PCR system using the following conditions: $50^{\circ} \mathrm{C}, 2 \mathrm{~min}$; $95^{\circ} \mathrm{C}, 10$ min; 40 cycles of $\left(95^{\circ} \mathrm{C}, 15 \mathrm{sec} ; 60^{\circ} \mathrm{C}, 1 \mathrm{~min}\right)$. Data were analyzed with the aid of SDS2.1 software (Applied Biosystems). The RNA quantity for each sample was normalized to $18 \mathrm{~S}$ in the same sample and then calibrated to P1. This provided an estimate of relative fold change compared to P1.

For the quantification of individual CPEB3 transcript variants, SYBR Green-based real-time PCR was used. MAPK1 was used for normalization. Transcript-specific, exonspanning primer sets were designed in house (table 1) using Vector NTI; PCR master mix containing the DNA polymerase, dNTPs, optimized buffer, and SYBR Green was obtained from Applied Biosystems. PCR reactions were performed with an ABI 7300 real-time PCR system under the following conditions: $95^{\circ} \mathrm{C}, 10 \mathrm{~min} ; 40$ cycles of $\left(95^{\circ} \mathrm{C}, 15 \mathrm{sec} ; 60^{\circ} \mathrm{C}, 1 \mathrm{~min}\right) ; 95^{\circ} \mathrm{C}, 15 \mathrm{sec} ; 60^{\circ} \mathrm{C}, 30$ sec; $95^{\circ} \mathrm{C}, 15 \mathrm{sec}$. Inclusion of the dissociation step would reveal nonspecific products and primer dimmer or duplexes, if any. When the specificity was validated, the following optimization steps were performed for each set of primers: the amount of forward/reverse primers (ranging from $50 \mathrm{nM} / 50 \mathrm{nM}$ to $900 \mathrm{nM} / 900 \mathrm{nM}$ ); the amount of cDNA (varying the dilution factors); the annealing temperature. Serial dilutions of a standard cDNA were used to generate standard curves, based which the amplification efficiencies were derived. Similarity within 5\% difference was considered acceptable for quantitative comparisons. The primers were then used in quantitative analysis of developmental samples. The relative quantity of RNA for CPEB3 was normalized to that of MAPK1 in the same sample. Data were analyzed with the aid of SDS2.1 software.

\section{In situ hybridization}

14 um frozen sections were used for in situ hybridization. Primers used in PCR amplification to generate the template for probes (IDT, Coralville, IA) are listed in table 3. PCR products were visualized on agarose gel and the specific band was cut out and purified using QIAquick Gel Extraction Kit (Qiagen, Valencia, CA). The identity of the purified product was confirmed by sequencing analysis, which was later used as template for in vitro transcription to generate DIG-labeled RNA probes (Invitrogen,
Carlsbad, CA). RNA probes were denatured at $85^{\circ} \mathrm{C}$ for 5 minutes then chilled on ice. Slides were treated with 0.1 M Rnase-free triethanolamine (TEA)-HCl pH 8.0 for 5 min, washed, and pre-hybridized at room temperature for an hour in hybridization buffer, which was then replaced with hybridization solution containing $100-200 \mathrm{ng} / \mathrm{ml}$ of RNA probes for overnight incubation at $65^{\circ} \mathrm{C}$. On the second day, slides were washed in $0.2 \times$ SSC several times then transferred to buffer B1 (0.1 M Tris, $0.5 \mathrm{M} \mathrm{NaCl}$, pH7.5) for 5 minutes. Slides were then incubated in buffer B2 (buffer B1 with 10\% heat-inactivated sheep serum) for 1 hour at room temp, after which buffer B2 was replaced with buffer B2 containing anti-DIG antibody (1:5000) for overnight incubation. On the third day, slides were washed, equilibrated in buffer B3 (0.1 M Tris, $0.1 \mathrm{M} \mathrm{NaCl}, 50 \mathrm{mM} \mathrm{MgCl}$, pH9.5), and colorization reaction was carried out in buffer B4 (buffer B3 with $20 \mu \mathrm{l}$ / $\mathrm{ml}$ NBT/BCIP stock solution and $0.1 \%$ tween-20). Slides were then mounted in Mowiol mounting medium and the results were analyzed with the aid of a microscope.

\section{Protein extraction}

Frozen retina was homogenized with the aid of a sonicator (Biologics, Inc., Manassas, VA) in CelLytic MT cell lysis buffer (Sigma, St. Louis, MO) with $1 \%(\mathrm{v} / \mathrm{v})$ protease inhibitor cocktail (Sigma). Samples were centrifuged at $1000 \times \mathrm{g}$ at $4^{\circ} \mathrm{C}$ for 10 minutes to remove tissue debris. Protein concentration in the supernatants was determined with the aid of the Bradford assay (Sigma, St. Louis, MO). The samples were then dispensed into aliquots and stored in $-80^{\circ} \mathrm{C}$.

\section{Western blots}

$25 \mu \mathrm{g}$ of total protein from each sample was loaded for each lane in polyacrylamide electrophoresis (PAGE) and gels were subsequently transferred to polyvinylidene fluoride (PVDF) membrane. GAPDH was used as a loading control. Antibodies were used at the indicated dilutions to label the western blots (table 4). Protein standards covering the range of $10 \mathrm{kD}$ to $250 \mathrm{kD}$ (Bio-Rad, Hercules, CA) were used as markers to determine the relative molecular weights of antibody labeled protein bands in western blots. Enhanced chemiluminescence reagent plus (ECL plus, Thermo Fisher Scientific, Rockford, IL) was used to detect the signal in the western blots. For negative controls

Table 3: Primers used to amplify probes for in situ hybridization.

\begin{tabular}{cll}
\hline Probe & Forward primer & Reverse primer \\
\hline CPEB3-antisense & 5'ACAGAGCCAGCTGCGCAAACCA3' & 5'GTAATACGACTCACTATAGGG \\
CPEB3-sense & 5'GTAATACGACTCACTATAGGG & GAAGGTGCCTCCGAAGACCG3' \\
& ACAGAGCCAGCTGCGCAAACCA3' & 5'GAAGGTGCCTCCGAAGACCG3' \\
\hline
\end{tabular}

The sequence in bold is T7 promoter. 
Table 4: Antibodies, sources, and working concentrations used in western blots.

\begin{tabular}{|c|c|c|c|}
\hline Antibodies & Catalog and Company & Species & Working Concentration \\
\hline CPEB3, polyclonal & $\begin{array}{l}\text { Abl0883 } \\
\text { Abcam, Cambridge, MA }\end{array}$ & Rabbit & $1: 1000$ \\
\hline GAPDH, monoclonal & $\begin{array}{l}\text { Img-5019A } \\
\text { Imgenex, San diego, CA }\end{array}$ & Mouse & I:5000 \\
\hline HRP conjugated secondary antibody, goat anti rabbit & $\begin{array}{l}\text { API87P } \\
\text { Millipore, Bedford, MA }\end{array}$ & Goat & $1: 30,000$ \\
\hline HRP conjugated secondary antibody, goat anti mouse & $\begin{array}{l}\text { API } 30 \mathrm{P} \\
\text { Millipore, Bedford, MA }\end{array}$ & Goat & $\mathrm{I}: 30,000$ \\
\hline
\end{tabular}

we used recombinant CPEB3 protein to pre-absorb the CPEB3 antibody.

To examine antibody specificity we used a recombinant CPEB3 protein to pre-adsorb the antibody. This served as a negative control. The recombinant protein was separated with electrophoresis and subjected to mass spectrometry (MS) for identity confirmation. The fusion protein was then purified and used as a blocking reagent for the CPEB3 antibody.

\section{Recombinant proteins}

Full-length CPEB3 cDNA was cloned into pGEX2T vector with a glutathionine S-transferase (GST) tag at the $5^{\prime}$ end (Keyclone, Cincinnati, $\mathrm{OH}$ ). The protein was induced in E. coli B2 1 cells by adding $0.8 \mathrm{mM}$ isopropyl $\beta$-D-1-thiogalactopyranoside (IPTG). Inclusion bodies were purified, solubilized with Inclusion Body Solubilization Reagent (Thermo Fisher Scientific, Rockford, IL), and dialyzed to physiological condition in a progressively reduced concentration of urea in Tris $\cdot \mathrm{HCl}$ (Thermo Fisher Scientific). The recombinant protein was used for preadsorption of antibody for western immunoblots to demonstrate specificity of the antibody.

\section{Immunohistochemistry}

$14 \mu \mathrm{m}$ frozen sections were used for immunohistochemistry. All steps were carried out at room temperature. Sections were treated with TBS (pH7.4) containing 0.05\% Triton X-100 for 10 minutes before being blocked with $10 \%$ normal donkey serum in TBS for 1 hour. Sections were then incubated with the primary antibodies at the indicated concentration for 1 hour. After several washes, secondary antibodies were applied for 1 hour. Slides were washed again before being cover-slipped with Vectashield mounting medium (Vector Laboratories, Burlingame, CA). Immunolabeled sections were photographed with the aid of a confocal microscope (Olympus, La Jolla, CA) using $40 \times$ objective. A stack of $1 \mu \mathrm{m}$ scans was combined to produce the final images. The antibodies used in this study, their source and dilutions are listed in table 5.

\section{siRNA knockdown of CPEB3}

Hela cells at confluence of 50-70\% were transfected with $100 \mathrm{nM}$ siRNAs duplexes using siPORT NeoFX reagent (Applied Biosystems, Foster City, CA) in serum-containing medium. Cells were incubated with siRNA-containing medium for 48 hours before being harvested. Proteins were extracted using CelLytic M Mammalian Cell Lysis/ Extraction Reagent (Sigma, St. Louis, MO) with $100 \times$ protease inhibitors (Thermo Fisher Scientific, Rockford, IL)

Table 5: Antibodies, sources, and working concentrations used in immunohistochemistry.

\begin{tabular}{|c|c|c|c|}
\hline Antibodies & Catalog and Source & Species & Working Concentration \\
\hline CPEB3, polyclonal & $\begin{array}{l}\text { Abl0883 } \\
\text { Abcam, Cambridge, MA }\end{array}$ & Rabbit & $\mathrm{I}: 50$ \\
\hline Mapla, monoclonal & $\begin{array}{l}\text { M4278 } \\
\text { Sigma,, St. Louis, MO }\end{array}$ & Mouse & $\mathrm{I}: 200$ \\
\hline ChAT, polyclonal & $\begin{array}{l}\text { API44-p } \\
\text { Millipore, Bedford, MA }\end{array}$ & Goat & $1: 200$ \\
\hline Alexa Fluor ${ }^{\circledR} 488$ donkey anti-rabbit $\lg G(\mathrm{H}+\mathrm{L})$ & $\begin{array}{l}\text { Allo34 } \\
\text { Invitrogen, Carlsbad, CA }\end{array}$ & Donkey & $\mathrm{I}: 200$ \\
\hline Alexa Fluor ${ }^{\circledR} 594$ donkey anti-mouse lgG & $\begin{array}{l}\text { A2 } 1203 \\
\text { Invitrogen, Carlsbad, CA }\end{array}$ & Donkey & $\mathrm{I}: 200$ \\
\hline Alexa Fluor ${ }^{\circledR} 594$ donkey anti-rabbit $\lg G(\mathrm{H}+\mathrm{L})$ & $\begin{array}{l}\text { A2 } 1207 \\
\text { Invitrogen, Carlsbad, CA }\end{array}$ & Donkey & $\mathrm{I}: 200$ \\
\hline Alexa Fluor ${ }^{\circledR} 488$ donkey anti-goat $\lg G$ & $\begin{array}{l}\text { All } 055 \\
\text { Invitrogen, Carlsbad, CA }\end{array}$ & Donkey & $1: 200$ \\
\hline
\end{tabular}


and used for western blots. The sequences of CPEB3 siRNA duplexes were as following: sense strand: CGAGUGGAACGCUACUCUAtt, antisense strand: UAGAGUAGCGUUCCACUCGtt. Silencer ${ }^{\circledR}$ Negative Control \#1 siRNA (Part Number AM4635, Applied Biosystems, Foster City, CA) was used as a negative control.

\section{Authors' contributions}

This was in partial fulfillment of the PhD degree of XPW. XPW has contributed to the conception and design, the experiments, the acquisition and analysis of data, and the drafting and revision of the manuscript. NGFC has contributed to the conception and design, the supervision of this study, the analysis and interpretation of data, the revision and final approval of the manuscript. NFGC also acquired funding for this project. All authors read and approved the final manuscript.

\section{Acknowledgements}

We thank Mr. Chris Whitaker for his assistance in immunohistochemistry, and Ms. Xiaohong Li for her assistance in sequencing service. We also gratefully acknowledge the service of the Bio Mass Spectrometry Core Laboratory at the University of Louisville. This study was supported in part by NEI ROIEYOI7594, NCRR P20 RRI648I and NIEHS P30ESOI 4443.

\section{References}

I. Gebauer F, Hentze MW: Molecular mechanisms of translational control. Nat Rev Mol Cell Biol 2004, 5:827-835.

2. Gebauer F, Richter JD: Mouse cytoplasmic polyadenylylation element binding protein: an evolutionarily conserved protein that interacts with the cytoplasmic polyadenylylation elements of c-mos mRNA. Proc Natl Acad Sci USA 1996, 93:|4602-|4607.

3. Good L: Translation repression by antisense sequences. Cell Mol Life Sci 2003, 60:854-86I.

4. Clegg KB, Piko L: RNA synthesis and cytoplasmic polyadenylation in the one-cell mouse embryo. Nature 1982, 295:343-344.

5. Clegg KB, Piko L: Quantitative aspects of RNA synthesis and polyadenylation in I-cell and 2-cell mouse embryos. J Embryol Exp Morphol 1983, 74:169-182.

6. Clegg KB, Piko L: Poly(A) length, cytoplasmic adenylation and synthesis of poly(A)+ RNA in early mouse embryos. Dev Biol 1983, 95:331-34I.

7. Wu L, Wells D, Tay J, Mendis D, Abbott MA, Barnitt A, Quinlan E, Heynen A, Fallon JR, Richter JD: CPEB-mediated cytoplasmic polyadenylation and the regulation of experience-dependent translation of alpha-CaMKII mRNA at synapses. Neuron 1998, 2 I: I I29-II39.

8. Kurihara Y, Tokuriki M, Myojin R, Hori T, Kuroiwa A, Matsuda Y, Sakurai T, Kimura M, Hecht NB, Uesugi S: CPEB2, a novel putative translational regulator in mouse haploid germ cells. Biol Reprod 2003, 69:261-268.

9. Theis M, Si K, Kandel ER: Two previously undescribed members of the mouse CPEB family of genes and their inducible expression in the principal cell layers of the hippocampus. Proc Natl Acad Sci USA 2003, I 00:9602-9607.

10. Huang YS, Kan MC, Lin CL, Richter JD: CPEB3 and CPEB4 in neurons: analysis of RNA-binding specificity and translational control of AMPA receptor GluR2 mRNA. EMBO J 2006, 25:4865-4876.

II. Rosenmund C, Clements JD, Westbrook GL: Nonuniform probability of glutamate release at a hippocampal synapse. Science 1993, 262:754-757.

12. Sala R, Viegi A, Rossi FM, Pizzorusso T, Bonanno G, Raiteri M, Maffei $L$ : Nerve growth factor and brain-derived neurotrophic factor increase neurotransmitter release in the rat visual cortex. Eur J Neurosci 1998, 10:2185-2191.
13. Yashiro K, Corlew R, Philpot BD: Visual deprivation modifies both presynaptic glutamate release and the composition of perisynaptic/extrasynaptic NMDA receptors in adult visual cortex. I Neurosci 2005, 25(50): I | 684- I I692.

14. Eliasieh K, Liets LC, Chalupa LM: Cellular reorganization in the human retina during normal aging. Invest Ophthalmol Vis Sci 2007, 48:2824-2830.

15. Tominaga-Yoshino K, Urakubo T, Okada M, Matsuda H, Ogura A: Repetitive induction of late-phase LTP produces long-lasting synaptic enhancement accompanied by synaptogenesis in cultured hippocampal slices. Hippocampus 2008, I 8:28I-293.

16. Cheetham CE, Hammond MS, McFarlane R, Finnerty GT: Altered sensory experience induces targeted rewiring of local excitatory connections in mature neocortex. I Neurosci 2008, 28:9249-9260.

17. Nicoll RA, Schmitz D: Synaptic plasticity at hippocampal mossy fibre synapses. Nat Rev Neurosci 2005, 6:863-876.

I8. Jorntell H, Hansel C: Synaptic memories upside down: bidirectional plasticity at cerebellar parallel fiber-Purkinje cell synapses. Neuron 2006, 52:227-238.

19. Karmarkar UR, Dan Y: Experience-dependent plasticity in adult visual cortex. Neuron 2006, 52:577-585.

20. Bisti S, Gargini C, Chalupa LM: Blockade of glutamate-mediated activity in the developing retina perturbs the functional segregation of ON and OFF pathways. J Neurosci 1998, I 8:5019-5025.

21. Bodnarenko SR, Chalupa LM: Stratification of ON and OFF ganglion cell dendrites depends on glutamate-mediated afferent activity in the developing retina. Nature 1993, 364: |44- | 46.

22. Tian N, Copenhagen DR: Visual stimulation is required for refinement of ON and OFF pathways in postnatal retina. Neuron 2003, 39:85-96.

23. Xue J, Li G, Laabich A, Cooper NG: Visual-mediated regulation of retinal CaMKII and its GluRI substrate is age-dependent. Brain Res Mol Brain Res 2001, 93:95-104.

24. Xue J, Cooper NG: The modification of NMDA receptors by visual experience in the rat retina is age dependent. Brain Res Mol Brain Res 2001, 91:196-203.

25. Vistamehr S, Tian N: Light deprivation suppresses the light response of inner retina in both young and adult mouse. Vis Neurosci 2004, 2 I :23-37.

26. Xia Y, Carroll RC, Nawy S: State-dependent AMPA receptor trafficking in the mammalian retina. I Neurosci 2006, 26:5028-5036.

27. Xia Y, Nawy S, Carroll RC: Activity-dependent synaptic plasticity in retinal ganglion cells. J Neurosci 2007, 27:| 222 I-I2229.

28. Liu LO, Li G, McCall MA, Cooper NG: Photoreceptor regulated expression of $\mathbf{C a ( 2 + ) / c a l m o d u l i n - d e p e n d e n t ~ p r o t e i n ~ k i n a s e ~}$ II in the mouse retina. Brain Res Mol Brain Res 2000, 82:I50-I66.

29. Kelly S, Yamamoto H, Robles LJ: Analysis of the 3' untranslated regions of alpha-tubulin and $S$-crystallin $m R N A$ and the identification of CPEB in dark- and light-adapted octopus retinas. Mol Vis 2008, I4: |446-|455.

30. Lin AC, Tan CL, Lin CL, Strochlic L, Huang YS, Richter JD, Holt CE: Cytoplasmic polyadenylation and cytoplasmic polyadenylation element-dependent $m$ RNA regulation are involved in Xenopus retinal axon development. Neural Dev 2009, 4:8.

31. Munton RP, Tweedie-Cullen R, Livingstone-Zatchej M, Weinandy F, Waidelich M, Longo D, Gehrig P, Potthast F, Rutishauser D, Gerrits B, Panse C, Schlapbach R, Mansuy IM: Qualitative and quantitative analyses of protein phosphorylation in naive and stimulated mouse synaptosomal preparations. Mol Cell Proteomics 2007, 6:283-293.

32. Darnell RB: Memory, synaptic translation, and...prions? Cell 2003, I I 5:767-768.

33. Si K, Lindquist S, Kandel ER: A neuronal isoform of the aplysia CPEB has prion-like properties. Cell 2003, I I 5:879-89 I.

34. Okabe S, Shiomura Y, Hirokawa N: Immunocytochemical localization of microtubule-associated proteins IA and 2 in the rat retina. Brain Res 1989, 483:335-346.

35. Tucker RP, Matus Al: Microtubule-associated proteins characteristic of embryonic brain are found in the adult mammalian retina. Dev Biol 1988, I30:423-434.

36. Eckenstein F, Thoenen H: Production of specific antisera and monoclonal antibodies to choline acetyltransferase: charac- 
terization and use for identification of cholinergic neurons. EMBO J 1982, I:363-368.

37. Tumosa N, Eckenstein F, Stell WK: Immunocytochemical localization of putative cholinergic neurons in the goldfish retina. Neurosci Lett 1984, 48:255-259.

38. Schmidt M, Wassle $H$, Humphrey M: Number and distribution of putative cholinergic neurons in the cat retina. Neurosci Lett 1985, 59:235-240.

39. Pourcho RG, Osman K: Cytochemical identification of cholinergic amacrine cells in cat retina. J Comp Neurol 1986, 247:497-504.

40. Tumosa N, Stell WK: Choline acetyltransferase immunoreactivity suggests that ganglion cells in the goldfish retina are not cholinergic. J Comp Neurol 1986, 244:267-275.

4I. Voigt T: Cholinergic amacrine cells in the rat retina. J Comp Neurol 1986, 248:19-35.

42. Wilczynska A, Aigueperse C, Kress M, Dautry F, Weil D: The translational regulator CPEB I provides a link between dcp I bodies and stress granules. J Cell Sci 2005, I I 8:98I-992.

43. Fisher LJ: Development of retinal synaptic arrays in the inner plexiform layer of dark-reared mice. J Embryol Exp Morphol 1979, 54:219-227.

44. Fisher LJ: Development of synaptic arrays in the inner plexiform layer of neonatal mouse retina. J Comp Neurol 1979, 187:359-372.

45. Sherry DM, Wang MM, Bates J, Frishman LJ): Expression of vesicular glutamate transporter $I$ in the mouse retina reveals temporal ordering in development of rod vs. cone and $\mathrm{ON}$ vs. OFF circuits. J Comp Neurol 2003, 465:480-498.

46. Rich KA, Zhan Y, Blanks JC: Migration and synaptogenesis of cone photoreceptors in the developing mouse retina. J Comp Neurol 1997, 388:47-63.

47. Chang YC, Chiao CC: Localization and functional mapping of AMPA receptor subunits in the developing rabbit retina. Invest Ophthalmol Vis Sci 2008, 49(I 2):5619-5628.

48. Grunder T, Kohler K, Guenther E: Distribution and developmental regulation of AMPA receptor subunit proteins in rat retina. Invest Ophthalmol Vis Sci 2000, 41:3600-3606.

49. Johansson K, Bruun A, Torngren M, Ehinger B: Development of glutamate receptor subunit 2 immunoreactivity in postnatal rat retina. Vis Neurosci 2000, 17:737-742.

50. Blanks JC, Bok D: An autoradiographic analysis of postnatal cell proliferation in the normal and degenerative mouse retina. J Comp Neurol 1977, 174:317-327.

5I. Sassoe-Pognetto $M$, Wassle $\mathrm{H}$ : Synaptogenesis in the rat retina: subcellular localization of glycine receptors, GABA(A) receptors, and the anchoring protein gephyrin. J Comp Neurol 1997, 38I: I58-I74.

52. Diao L, Sun W, Deng Q, He S: Development of the mouse retina: emerging morphological diversity of the ganglion cells. Neurobiol 2004, 61:236-249.

53. Tian N, Copenhagen DR: Visual deprivation alters development of synaptic function in inner retina after eye opening. Neuron 2001, 32:439-449.

54. Biou V, Bhattacharyya S, Malenka RC: Endocytosis and recycling of AMPA receptors lacking GluR2/3. Proc Natl Acad Sci USA 2008, 105:1038-1043.

55. Luscher C, Xia H, Beattie EC, Carroll RC, von ZM, Malenka RC, Nicoll RA: Role of AMPA receptor cycling in synaptic transmission and plasticity. Neuron 1999, 24:649-658.

56. The UniGene Database [http://www.ncbi.nlm.nih.gov/sites/ent rez]

57. The UCSC Genome Browser Database [http:// genome.ucsc.edu/]

58. The UCSC Mouse Proteome Database [http:// genome.ucsc.edu/]

59. The UniProt Database [http://www.uniprot.org]

60. The NCBI Protein Database [http://www.ncbi.nlm.nih.gov/sites/ entrez]

61. The Blast [http://blast.ncbi.nlm.nih.gov/Blast.cgi]

62. The UCSC Blat [http://genome.ucsc.edu/cgi-bin/hgBlat]
Publish with Bio Med Central and every scientist can read your work free of charge

"BioMed Central will be the most significant development for disseminating the results of biomedical research in our lifetime. "

Sir Paul Nurse, Cancer Research UK

Your research papers will be:

- available free of charge to the entire biomedical community

- peer reviewed and published immediately upon acceptance

- cited in PubMed and archived on PubMed Central

- yours - you keep the copyright
BioMedcentral 